\title{
Considerações sobre a terceira idade e o mercado de trabalho: questionamentos e possibilidades
}

\author{
Edward Goulart Júnior", Lucila Russi Mergulhão", Luiz Carlos Canêo*”, Marielly Bueno Najm”*”, \\ Maria Cristina Frollini Lunardelli ${ }^{* * * * *}$
}

\section{Resumo}

Esse trabalho tem como objetivo refletir sobre a questão do envelhecimento do indivíduo e a possibilidade de este permanecer no mercado de trabalho, discutindo a importância do trabalho na terceira idade para a saúde do sujeito tanto física quanto mental. A aposentadoria é vista como um processo de mudança, que pode significar perda de identidade ou procura de outras fontes de desenvolvimento, como, por exemplo, saúde e lazer, ou seja, um sentido para a vida fora do trabalho. Destacamse também o processo de educação para o envelhecimento do indivíduo no trabalho, que é um dos papéis do psicólogo organizacional, agindo em conjunto com políticas públicas adequadas, que irão garantir as condições objetivas necessárias para a permanência do idoso no mercado, e a conscientização da população para a valo- rização do idoso como fontes de desenvolvimento físico, mental e emocional desta.

Palavras-chave: Envelhecimento. Mercado de trabalho. Aposentadoria. Políticas públicas. Psicólogo.

\section{Introdução}

O envelhecimento é um fenômeno que está relacionado à vida de todos os seres vivos, e na espécie humana está atrelado às suas condições de vida e trabalho. É um processo que ocorre de maneira singular para cada indivíduo e, embora esteja vinculado a uma série de alterações biológicas que lhe impõem alguma dificuldade, não necessariamente está vinculado apenas a perdas

* Doutor em Psicologia pela Pontifícia Universidade Católica de Campinas. Professor do curso de Psicologia da Universidade Estadual Paulista, campus de Bauru.

*** Graduada em Psicologia pela Universidade Estadual Paulista, campus de Bauru.

**** Doutor em Educação pela Universidade Federal de São Carlos. Professor do curso de Psicologia da Universidade Estadual Paulista, Campus de Bauru.

***** Licenciada em Psicologia pela Universidade Estadual Paulista, Campus de Bauru.

****** Doutora em Educação pela Universidade Estadual Paulista Júlio de Mesquita Filho. Professora do curso de Psicologia da Universidade Estadual Paulista, Campus de Bauru. Endereço para correspondência: Universidade Estadual Paulista Júlio de Mesquita Filho, Faculdade de Ciências de Bauru, Departamento de Psicologia. Avenida Luiz Edmundo Carrijo Coube, s/n, Vargem Limpa, Bauru - SP, CEP 17033-360, Caixa Postal 473. E-mail: dpsi@fc.unesp.br ou mlunardelli@uol.com.br

$\longrightarrow$ Recebido em setembro de 2008 - Avaliado em agosto de 2009.

$\hookrightarrow$ doi:10.5335/rbceh.2009.042 
e limitações; pelo contrário, pode se caracterizar como um período de intensa funcionalidade cognitiva, afetiva e física, caso haja oportunidade para tal. (NERI apud OLIVEIRA; OLIVEIRA; WAJNMAN, 2004).

Pessoa (2006) argumenta que, conforme o Censo 2000, realizado pelo Instituto Brasileiro de Geografia e Estatística, 14,5 milhões de pessoas no Brasil (8,6\% da população total) são idosas - denominação atribuída àqueles que possuem sessenta anos ou mais. Estimase ainda que, em 2020, essa população atinja 30,9 milhões de pessoas (13\% do total), e a expectativa de vida, 70,3 anos. Com esse aumento da expectativa de vida é inevitável a ampliação da participação de pessoas idosas na população economicamente ativa (PEA) do país.

Diante disso, é importante ressaltar que o trabalho é fator determinante para o desenvolvimento humano, na medida em que é por meio dele que se constrói a identidade do sujeito, a qual fornece sentido à sua existência como ser social. Assim, devemos considerar a importância da inclusão da pessoa idosa no mercado de trabalho. Para tanto, torna-se imprescindível a garantia de políticas públicas que atendam essas pessoas, dando-lhes condições adequadas para exercerem seu potencial. Muitas delas possuem disposição e saúde para trabalhar aos sessenta anos de idade, pois os avanços da medicina trouxeram melhores condições física e mental aos indivíduos.

O presente estudo visa caracterizar o modo como vem ocorrendo o processo de envelhecimento no Brasil e suas consequências para a saúde mental do tra- balhador, bem como as contribuições da psicologia, principalmente da psicologia organizacional e do trabalho, quanto ao processo de educação para o envelhecimento do indivíduo no trabalho - em conjunto com políticas públicas adequadas -, visando à permanência do idoso no mercado, além de seu desenvolvimento físico, mental e emocional.

\section{0 idoso, o mercado de trabalho e}

\section{a aposentadoria}

Segundo Bosi (2001, p. 76), a velhice vem sendo vivida e compreendida como estágio de ausência de ação, fase de rememoração, ou quando os sujeitos estão cansados de atividade. Os idosos são postos à margem ao cumprirem a sua função - preparar e treinar aqueles que irão substituí-los, muitas vezes superando-os. Quando isso acontece, seus "aprendizes", normalmente, lhes dão as costas, seguindo a "lei da superação da geração mais velha pela mais jovem".

Vivemos num momento histórico em que velhos são rejeitados por não serem mais considerados produtores. Quando se vive o primado da mercadoria sobre o homem e se tem na força de trabalho a valorização humana, o aumento da idade é acompanhado por desvalorização. A ideia de que o idoso não pode fazer nada e não participa mais de nenhuma produção é introjetada pelas pessoas, de forma que elas próprias delineiem seu futuro passivo. (BASTOS; BORGESANDRADE; ZANELLI, 2004).

Hoje em dia o mercado de trabalho não compreende como utilizar as capacidades dessas pessoas com idade mais 
avançada, apesar de elas desejarem permanecer como seres produtivos. (PESSOA, 2006). Para estas, as pessoas mais jovens são tidas como mais ágeis, produtivas, flexíveis e habituadas com as novas tecnologias, desvalorizando, assim, o idoso. E quando este vai procurar trabalho, as oportunidades que aparecem são subempregos instáveis e de posição inferior às que anteriormente ocupavam, além de uma remuneração mais baixa se comparada com a dos demais trabalhadores. A ideologia social com visão desprestigiada da pessoa idosa - e suas consequências - acaba por colaborar para que ela própria acredite estar em uma fase inútil, julgando-se incapaz e improdutiva e aumentando, assim, a desesperança. (GOLDIN; MALDONADO, 2000; PESSOA, 2006).

$\mathrm{Na}$ sociedade capitalista, que valoriza a produção e o consumo, o trabalho (emprego) tem papel obrigatório e prioritário na vida dos indivíduos. Dessa forma, o papel profissional se inscreve na identidade do sujeito. Enquanto papel social, o trabalho assume várias funções na vida do indivíduo: interfere na construção de sua identidade, é determinante no lugar que ele ocupa no sistema de produção, é fonte de renda, atividade e relacionamento interpessoal.

A partir do momento em que esgota sua força de trabalho, o homem perde um objetivo de vida e acaba aceitando a aposentadoria como um favor. A esse respeito, Bosi (2001, p. 80) afirma o seguinte:

Durante a velhice deveríamos estar ainda engajados em causas que nos transcendem, que não envelhecem, e que dão significado a nossos gestos cotidianos. Talvez seja esse um remédio contra os danos do tempo. Mas [...] se o trabalhador aposentado se desespera com a falta de sentido da vida presente, é porque em todo o tempo o sentido de sua vida lhe foi roubado.

Assim, a perda do trabalho - o momento da aposentadoria - representa a exclusão do sujeito do mundo produtivo e implica a reestruturação espacial e temporal de sua vida. Ao se aposentar, o sujeito deve elaborar o luto pela perda da identidade profissional, da fonte de reconhecimento e aceitação. Por isso, a exclusão do idoso do meio produtivo, em geral, associa-se a diversos sentimentos negativos (de depressão e desvalorização), podendo tornar este momento desencadeador de sofrimento. (LEÓN, 2000; SANTOS, 1990).

Soma-se a isso o fato de a aposentadoria acarretar outras mudanças - muitas delas imprevistas -, como alterações na estrutura familiar, pois a organização e rotina já estabelecidas não incluem a presença do aposentado. Isso acaba gerando conflitos entre seus membros, que não estavam habituados com a convivência diária com aquela pessoa. A quantidade de tempo livre pode também aparecer como motivo gerador de sofrimento.

Outro fato intrinsecamente ligado à aposentadoria é a perda da rede social de amigos e companheiros de trabalho, com os quais por muitos anos o convívio foi diário e intenso e, com o término das atividades, esse vínculo é interrompido. (LEÓN, 2000).

Esses sentimentos de inutilidade, solidão e dificuldade de inserção ou manutenção no mercado de trabalho fizeram 
surgir instituições de assistência aos idosos, como casas de repouso ou asilos, que oferecem atividades para preencher o tempo ocioso de seus usuários - na maioria das vezes, porém, essas atividades os infantilizam ou ridicularizam. Outro ponto a ser destacado é que esses locais de integração são frequentados apenas por idosos, o que impede um intercâmbio de conhecimentos e experiências entre as gerações, contribuindo, necessariamente, para a exclusão dessa parcela da população. Diante disso, a perda da identidade e a exclusão social só poderiam colaborar para intensificar o processo de marginalização desses indivíduos. (GOLDMAN, 2003).

A aposentadoria, como qualquer outra mudança de vida, coloca a pessoa diante de uma encruzilhada: a nova situação pode ser tomada como uma catástrofe, um perigo, ao ser considerada um castigo por significar o não-poder-fazer mais nada em sua vida; mas também pode significar uma oportunidade, a possibilidade de construir novos projetos ou retomar antigos. (MALDONADO; GOLDIN, 2000).

$\mathrm{E}$, diante do impacto causado pelo desligamento do trabalho na vida do sujeito, diversas instituições e empresas têm investido na criação de programas para quem vai se aposentar. O psicólogo organizacional pode atuar nesse processo promover a reflexão e preparação para a aposentadoria por meio de programas, buscando melhorar a qualidade de vida. É necessário refletir acerca dos aspectos positivos e negativos da nova etapa, para que haja um enfrentamento mais consciente e a criação de novos objetivos, habilitando os indivíduos a aumentarem o controle sobre suas vidas. Daí a importância de uma equipe multiprofissional, envolvendo médicos (geriatras, oftalmologistas, reumatologistas, ortopedistas, otorrinolaringologistas, etc.), fonoaudiólogos, fisioterapeutas, terapeutas ocupacionais, advogados, entre outros, para que seja possível abranger as diversas áreas atuantes no processo.

\section{Importância do trabalho na terceira idade}

Para Argimon, Lopes e Nascimento (2001), é comprovada a importância do trabalho na qualidade de vida dos idosos, já que influencia no desenvolvimento físico, cognitivo e emocional destes. Além disso, quando o trabalho é atrelado à ideia de satisfação e realização pessoal, as possibilidades de uma sobrevida mais digna e saudável são maiores, além de se preservar o papel social do sujeito em seu próprio meio.

Segundo Giatti e Barreto (2003), inúmeras pesquisas demonstram que as pessoas que trabalham apresentam melhores condições de saúde do que a população geral - isso também entre os idosos; uma melhor condição de saúde está positivamente associada ao trabalho. De acordo com os autores, o não trabalho tem sido associado a maiores taxas de mortalidade e maior prevalência de sintomas psiquiátricos, de hipertensão arterial e hábitos de vida nocivos, como consumo de bebida alcoólica e cigarro.

Estudo realizado por esses autores com 2886 idosos de 65 anos ou mais, residentes em dez regiões metropolita- 
nas brasileiras, constatou que a maioria deles $(68,46 \%)$ estava aposentada e não trabalhava, 26,9\% trabalhavam (sendo estes aposentados ou não) e 4,6\% não trabalhavam e nem eram aposentados. Os inativos que tinham alguma ocupação apresentaram melhores condições de saúde, menor dificuldade para executar tarefas diárias, maior autonomia e mobilidade física e, além disso, possuíam maior escolaridade e renda per capita.

Dessa forma, um ponto a ser considerado para a chance de manutenção do idoso no mercado de trabalho após a aposentadoria é seu nível de escolaridade e qualificação profissional. Assim, as desvantagens constituídas desde o início da vida continuam operando até mesmo na velhice, já que a escolaridade contribui para um trabalho mais qualificado, melhor remuneração e aumento do tempo laboral. Dessa maneira, como a capacidade de trabalho e a qualidade de vida dos idosos são determinadas, em grande parte, por etapas anteriores da vida, alterações positivas na vida dos idosos consistem em investimentos na educação, saúde e trabalho para os jovens e adultos de hoje. (GIATTI; BARRETO, 2003).

Pesquisa realizada por Wajnman et al. (2004) caracterizou a atividade econômica dos idosos, indicando tanto os subgrupos de maior participação quanto os tipos de atividade em que os idosos tendem a se concentrar. Verificou-se que os idosos mais disponíveis para o trabalho (o que se reflete nas maiores taxas de atividade) são aqueles mais dependentes do rendimento da atividade econômica: os homens, os negros, os chefes de família, os de menor renda familiar, os não aposentados e os trabalhadores das ocupações manuais. Todavia, são os trabalhadores mais escolarizados os que encontram a maior probabilidade de se manter ocupados nas idades avançadas. Do ponto de vista da estrutura ocupacional do mercado de trabalho dos idosos, apontou-se a predominância destes nas atividades agrícolas e de serviços, nas posições de conta-própria e sem-remuneração (sobretudo para as mulheres do meio rural) e nas ocupações manuais.

Em termos de tendências recentes, deve ser ressaltado o expressivo crescimento da proporção de aposentados entre os idosos economicamente ativos, como decorrência da ampliação da cobertura previdenciária pós-Constituição de 1988. Entre os anos de 1981 e 2001, a proporção de aposentados acima de sessenta anos de idade cresceu de $49 \%$ para $68 \%$ no meio urbano e de $59 \%$ para $92 \%$ no rural. Entre as mulheres, esse aumento foi de $39 \%$ para $49 \%$ no meio urbano e de $43 \%$ para $79 \%$ no meio rural. Entretanto, esse crescimento significativo da cobertura previdenciária, sobretudo rural, não teve o impacto esperado sobre a atividade econômica, ou seja, o benefício da aposentadoria, embora se transformasse em um importante instrumento de geração de renda familiar e combate à pobreza, aparentemente não gerou nenhum incentivo ao afastamento do trabalho. (OLIVEIRA; OLIVEIRA; WAJNMAN, 2004).

A tendência de manutenção dos níveis de atividade dos idosos é reforçada pela evidência de que a ampliação do principal incentivo financeiro ao afas- 
tamento do trabalho - o benefício da aposentadoria - não parece estar produzindo esse resultado. A justificativa mais plausível para essa tendência é o impacto da renda do idoso (tanto a fatia proveniente da aposentadoria quanto a do trabalho) em sua renda familiar. (OLIVEIRA; OLIVEIRA; WAJNMAN, 2004).

\section{Saúde, trabalho e educação no processo de envelhecimento}

Em qualquer situação deve ser analisado o significado do trabalho para quem vai se aposentar. $O$ trabalho pode ser fonte de prazer ou apenas uma forma de sobrevivência. Nem todos os trabalhadores tiveram a oportunidade de escolher suas profissões ou mesmo de ter um emprego satisfatório. Alguns não puderam investir muito tempo ou dinheiro na educação e a escolha da atividade era determinada por aspectos pragmáticos (a mais prática, rápida e rentável possível). Mesmo para aqueles que puderam investir na futura profissão, grande parte pode ter sido influenciada pela família. (FRANÇA, 1999).

Entretanto, mesmo que a profissão não tenha sido planejada, as pessoas acabam se adaptando a determinadas situações implícitas no trabalho. O salário em si, o prazer do próprio "fazer", o ambiente, o percurso para o trabalho, o status e o poder que alguns cargos conferem, as relações com os colegas e os clientes e mesmo o mobiliário e os equipamentos do trabalho fazem parte de uma história de vida da qual o indivíduo muitas vezes não quer se desligar, até porque nem sempre identifica as possibilidades de substituição. Abdicar de tudo relacionado ao trabalho pode ser muito difícil. Além disso, existem pessoas que constroem toda a sua identidade vinculada apenas a uma área de interesse: o trabalho. A definição de si próprias e a forma como se apresentam a alguém acabam ocorrendo, invariavelmente, em função da profissão exercida. (FRANÇA, 1999).

Segundo pesquisa realizada por Jaime Lisandro Pacheco (2002), pessoas que tiveram sua formação educacional totalmente voltada para ser produtivo (com o pensamento de que só o trabalho é capaz de valorizar um indivíduo) são aquelas que apresentam maiores chances de sofrimento com a depressão. Entre estes, os homens apresentam mais sintomas depressivos que as mulheres, já que têm sua imagem de sucesso e de autoestima extremamente vinculadas ao trabalho. As mulheres, por serem vistas culturalmente como "ajudantes" no orçamento da casa, mesmo que tenham deixado sua ocupação no mercado de trabalho, não perdem sua "função" no mundo. Isso mostra que, mesmo depois que deixarem seus trabalhos formais, é importante que as pessoas encontrem outra forma de se posicionar perante $o$ mundo externo.

Segundo Antunes (2005), é importante considerar que o ser humano se desenvolve não só por meio do trabalho, mas também a partir de outras atividades - arte, literatura, música - e do ócio, pois elas lhe permitem emancipar-se em seu sentido mais profundo. Por isso, é importante uma educação voltada também 
para outras fontes de desenvolvimento, não só para a produtividade e a entrada no mercado de trabalho. A valorização do indivíduo e o sentido que este impõe a sua vida devem perpassar por questões que vão além do trabalho. O lazer e os cuidados com a saúde são, também, categorias importantes para o desenvolvimento do sujeito, pois, se o idoso possui outras fontes de sentido para sua vida, o sofrimento pode ser reduzido ao parar de trabalhar.

Para Goldman (2003), as condições objetivas de vida da população interferem diretamente no envelhecimento, por meio da qualidade oferecida aos que envelhecem. Há necessidade de se pensarem cuidadosamente políticas de emprego focadas nesse contingente populacional.

No que concerne às políticas públicas relacionadas ao envelhecimento, $o$ artigo 26 do Estatuto do Idoso prevê que as pessoas com mais de sessenta anos têm direito ao exercício de atividade profissional, respeitadas suas condições físicas, intelectuais e psíquicas

A mesma lei define que são vedadas a discriminação e a fixação de limite máximo de idade para o exercício de qualquer emprego, inclusive em concursos públicos, salvo os casos em que a natureza do cargo o exigir (casos em que é necessário grande esforço físico). Além disso, conforme o art. 27, o primeiro critério de desempate nos exames será a idade, dando-se preferência ao de idade mais elevada.

É ainda assegurado pela Constituição que o poder público deve criar programas de profissionalização para os idosos, aproveitando seus potenciais e habilidades para atividades regulares e remuneradas. E ainda, devem ser oferecidos programas de preparação para a aposentadoria, com antecedência mínima de um ano, por meio de estímulo a novos projetos e esclarecimentos sociais e de cidadania (art. 28).

Essas considerações estão na lei, porém na prática não estão sendo aplicadas. Como apresentado acima, pesquisas recentes revelam que a participação do idoso no mercado de trabalho é importante não só em termos de seu impacto na PEA, mas também em sua qualidade de vida, ressaltando a importância do trabalho do e para o idoso.

Cabe lembrar também a importância de o sujeito encontrar outras formas de se posicionar perante o mundo após deixar seu trabalho formal a fim de preservar sua saúde.

Diante do contexto apresentado, algumas iniciativas de reação devem ser tomadas a fim de preservar a autoestima da pessoa idosa de forma que esta não adoeça ao "perder" seu trabalho. Assim, o psicólogo pode atuar no processo de préaposentadoria, promovendo a reflexão e preparação por meio de programas que visem buscar a promoção da qualidade de vida, dando-lhes a oportunidade de construção de novas alternativas de vida pessoal, profissional e pós-carreira. Pode também promover a atualização profissional por meio de cursos, palestras, a fim de garantir o aprimoramento profissional dos indivíduos. 


\section{Considerações finais}

A sociedade em que vivemos, de forma geral, possui uma visão preconceituosa sobre o processo de envelhecimento, principalmente no que se refere ao mercado de trabalho, já que este se pauta em maior produção e lucro - e a velhice é vista como estágio de incapacidade e improdutividade. Por isso, o idoso internaliza essa ideologia, na medida em que assume uma postura passiva diante da sua "substituição" pelos mais novos.

No entanto, é de suma importância retomar o papel ativo desse estágio da vida, que deve ser entendido ainda como momento propício à continuidade de aprendizagem e ao desenvolvimento humano. Idosos em boas condições de saúde e com autonomia física e mental mantêm boas perspectivas de vida e podem assumir papéis relevantes na sociedade. Cabe à sociedade levar em consideração a capacidade de trabalho dos idosos e garantir o direito à manutenção ou reinserção no mercado de trabalho daqueles que assim o desejarem.

Além disso, como o psicólogo na organização trabalha com a qualidade de vida e saúde mental do trabalhador, acompanha a vida profissional do sujeito desde sua contratação até a sua aposentadoria - seja ele jovem, adulto ou idoso. E, por meio dos processos de educação para $o$ trabalho (treinamento, desenvolvimento e promoção de práticas emergentes), pode propiciar um desenvolvimento contínuo do indivíduo, tanto profissional quanto pessoal, colaborando, assim, com a saúde mental e permanência desse no mercado formal.
A participação do idoso brasileiro no mercado de trabalho acaba ocorrendo basicamente pelo fato de que, no Brasil, o aposentado ganha pouco e às vezes, mesmo que não queira, precisa continuar trabalhando para se sustentar. O idoso tem direito ao trabalho digno, mas, para que isto seja possível, é preciso que haja políticas públicas que garantam condições objetivas para tal, assim como a sociedade precisa aprender a valorizar a experiência dos idosos.

Considerations on the third age and the labour market: questions and possibilities

\section{Abstract}

This work has how to reflect the question of the aging of the individual and the possibility of this to remain in the labor market, discussing the importance of the work in the third age, so much for the physical health how much mental of the subject. The retirement is seen how a process of change, which can mean loss of identity or it looks of other fountains of development, like for example health and leisure, in other words, a sense for the life out of the work. Detach, also, the process of education for the aging of the individual in the work, what is one of the papers of the organizational psychologist, acting together with public appropriate politics, what will go guaranteed the objective necessary conditions for the permanence of the old one in the market, and to make aware the population for the increase in value of the old one, like fountains of physical, mental and emotional development of this population.

Key words: Aging. Job market. Retirement. Public politics. Acting out. 


\section{Referências}

ANTUNES, R. Os sentidos do trabalho. São Paulo: Boitempo, 2005.

ARGIMON, I. I. L.; LOPES, R. M. F; NASCIMENTO, R. F. L. Atualidades sobre o idoso no mercado de trabalho. 2006. Disponível em: <www.psicologia.com.pt/artigos/textos/ A0300.pdf.>. Acesso em: 15 mar. 2008.

BASTOS, A. V. B.; BORGES-ANDRADE, J. E.; ZANELLI, J. C. (Org.). Psicologia, organizações e trabalho no Brasil. Porto Alegre: Artmed, 2004.

BOSI, E. Memória e sociedade. São Paulo: Companhia das Letras, 2001.

BOTELHO, M. I. V.; COELHO, F. M. G.; SIQUEIRA, R. L. A velhice: algumas considerações teóricas e conceituais. 2002. Disponível em: <www.scielo.br/scielo.php>. Acesso em: 21 fev. 2008.

CAMARANO, A. A. O idoso brasileiro no mercado de trabalho. 2001. Disponível em: <www.ipea.gov.br/pub/td/2001/td_0830.pdf>. Acesso em: 15 mar. 2008.

CÉSPEDES, L.; PINTO, A. L. T.; WINDT, M. C. V. S. (Org.). Vade mecum. 3. ed. São Paulo: Saraiva, 2007.

FRANÇA, L. H. Preparação para aposentadoria: desafios a enfrentar. In: VERAS, R. P. (Org.). Terceira idade: alternativas para uma sociedade em transição. Rio de Janeiro: Relume-Dumará/Unati/UERJ, 1999. p. 11-34.

GIATTI, L.; BARRETO, S. M. Trabalho feminino e saúde na terceira idade. Ciência \& Saúde Coletiva, Rio de Janeiro, v. 7, n. 4, p. 825-839, 2002. Disponível em: <www.scielo. br/scielo.php?script=sci_arttext\&pid=S1413$81232002000400016 \& l n g=p t \& n r m=i s o>$. Acesso em: 18 fev. 2008. DOI: 10.1590/S141381232002000400016.

GIATTI, L.; BARRETO, S. M. Saúde, trabalho e envelhecimento no Brasil. Cadernos de Saúde Pública, Rio de Janeiro, v. 19, n. 3, mai./jun. 2003. Disponível em: <www.scielo.
br/scielo.php?script=sci_arttext\&pid=S0102$311 X 2003000300008 \& \operatorname{lng}=$ pt\&nrm $=$ iso $>$. Acesso em: 20 fev. 2008. DOI: 10.1590/S0102311X2003000300008.

GOLDIN, A.; MALDONADO, M. T. Maiores de 40 : guia de viagem para a vida. São Paulo: Saraiva, 2000.

GOLDMAN, S. N. Aspectos sociais e políticos do envelhecimento. 2003. Disponível em: <www.sbggrj.org.br/Biblioteca/gerontologia. asp>. Acesso em: 19 mar. 2008.

LEÓN, L. M. Pensando na qualidade de vida ao aposentar. In: GUIMARÃES, L. A. M.; GRUBITS, S. (Org.). Saúde mental e trabalho. São Paulo: Casa do Psicólogo, 2000. p. 95-105.

PACHECO, J. L. Educação, trabalho e envelhecimento: estudo das histórias de vida de trabalhadores assalariados, após a aposentadoria. 2002. 424 f. Tese (Doutorado em Educação) - Faculdade de Educação da Universidade Estadual de Campinas. Campinas, 2002.

PESSOA, E. M. Idosos: trabalho e aposentadoria. 2006. Disponível em: <www.reitoria. uri.br/ vivencias/Numero_004>. Acesso em: 20 fev. 2008.

SANTOS, M. F. Identidade e aposentadoria. São Paulo: EPU, 1990.

OLIVEIRA, A. M.; OLIVEIRA, E. L.; WAJNMAN, S. Os idosos no mercado de trabalho: tendências e conseqüências. In: CAMARANO, A. A. (Org.). Os novos idosos brasileiros: muito além dos 60? Rio de Janeiro: Ipea, 2004. Disponível em: <www.ipea.gov. br/sites/000/2/livros/idososalem60/Arq_23_ Cap_14.pdf.>. Acesso em: 18 mar. 2008. 